\title{
Research on Simulation Model of Wind Speed Change before and after Protection Forest Belt
}

\author{
Xiaoye $\mathrm{Li}^{1}$, Kejian Wang ${ }^{1,{ }^{*}}$, Hao Tang ${ }^{1}$, Jiancai $\mathrm{Gu}^{2}$ and Zhenxue $\mathrm{He}^{1}$ \\ ${ }^{1}$ College of Information Science and Technology, Agriculture University of Hebei, Baoding, China \\ ${ }^{2}$ Forestry College, Agriculture University of Hebei, Baoding, China \\ ${ }^{*}$ Corresponding author
}

Keywords: Simulation model, Wind tunnel experiments, Least squares method, Ridge regression, Elastic network.

\begin{abstract}
Reducing wind speed is the main role of shelterbelt. To reveal wind speed change characteristics in the protected area, establish a simulation model of the average wind speed, height and average wind speed after the forest belt. Established three wind speed variation models respectively by the least squares method, ridge regression and elastic network method. Verified the wind speeds of the windward and leeward sides of eight different structural forests under wind speeds of 8,11 and $14 \mathrm{~m} \cdot \mathrm{s}^{-1}$ by wind tunnel experiments. Model evaluation indicators are the coefficient of determination $\left(\mathrm{R}^{2}\right)$ and root mean square error(RMSE). The results show that the $\mathrm{R}^{2}$ of models all are higher than 0.9, and RMSE are 1.05492, 1.05490 and 1.05092 in turn. Comparing the modeling performance of three methods, the generalization ability of elastic network is better. The average of $0-5 \mathrm{H}$ wind speed before the forest belt and height can estimate the average wind speed after $0-10 \mathrm{H}$ the forest belt.
\end{abstract}

\section{Introduction}

The shelterbelt is a forest type based on the forest ecological service function ${ }^{[1]}$. The windbreak can effectively reduce the wind speed and form a protected area after the forest belt. Many domestic and foreign scholars have studied the wind speed distribution after windbreaks through field observation experiments, wind tunnel experiments or numerical simulation techniques ${ }^{[2]}$.

Zhang et al. observed the wind speed of forest net under five different wind directions under two wind speeds in the field. The wind speed was analyzed by mathematical expectation method found that with the decrease of the angle between the wind direction and the main forest belt, the average wind speed showed an increasing trend, which provided a basis for the construction of farmland shelterbelt ${ }^{[3]}$. Niu et al. used the spatial multi-point observation method to observe the wind speed distribution in the field experiment. It was found that when the wind speed in the field was 3.84 $\mathrm{m} \cdot \mathrm{s}^{-1}$, the wind speed of each heights in the leeward first decreased and then increased ${ }^{[4]}$.

Rosenfeld et al. constructed a 3D cypress tree model by numerical simulation technology (CFD), and analyzed the windbreak layout of single row of infinite long cypress trees and two rows of infinite cypress trees. It is concluded that the wind speed of single row cypress canopy decreases near the edge of the forest edge; the wind speed of the stem near the ground increased. The wind speed of the two rows of cypress windbreaks was more obvious than that of the single row ${ }^{[5]}$.

Takahash used wind tunnels to simulate wind speed the distribution solid barriers of three different widths and distributions and three different widths of porous windbreaks. It is found that the narrower single-row or multi-row solid barrier leeward wind speed decreases with increasing distance. The larger single-row solid barrier wind speed increases rapidly with distance, and the turbulent area is closer to the solid barriers than the former two, while the minimum wind speed which porous shelterbelt of the three different widths are different position, but after, the wind speed increases with the same proportion with the distance ${ }^{[6]}$.

Cheng et al. measured the wind speed of eight different characteristics of single plant belts under three wind speed gradients by wind tunnel test, compared the wind speeds at different distances and heights after the forest belt, corrected the relaxation equation of individual plants airflow recovery 
on the leeward side and establishing a linear function of minimum wind speed and forest belt structure after forest ${ }^{[7]}$.

Lee et al. used the particle image velocimetry(PIV) technique to quantitatively measure the entire velocity field of the flow around the cedar tree placed in the wind tunnel test area, and compared the influence with or without leaves on the wind speed in the leeward, indicating that the leaves can reduce the porosity of the canopy to enhances the wind speed reduction effect in the leeward region $^{[8]}$.

Previous studies have analyzed the distribution trend of wind speed before and after windbreaks, and discussed the wind speed distribution of windbreaks under different forest belt structures. However, the simulation model for the relationship between the average wind speed on the windward surface and the height of the detection point and the average wind speed in the leeward has not been determined.

Based on the wind tunnel experimental observation, this study uses the least squares method, the ridge regression and the elastic network algorithm to establish the wind speed model to predict the shelterbelt wind speed in the leeward.

\section{Data Acquisition}

\section{Experimental Equipment and Materials}

The wind tunnel experiment was carried out in the wind tunnel experimental system of Beijing Forestry University that is the Key Laboratory of Soil and Water Conservation and Deserification Prevention and Control(refer with: Fig. 1). The trees employed are Larch with 8 kinds of different structures(refer with: Table 1). The windbreak forest used a soft simulated plant that is $10 \mathrm{~cm}$ high. Its ratio to the natural plant is $1: 100$.

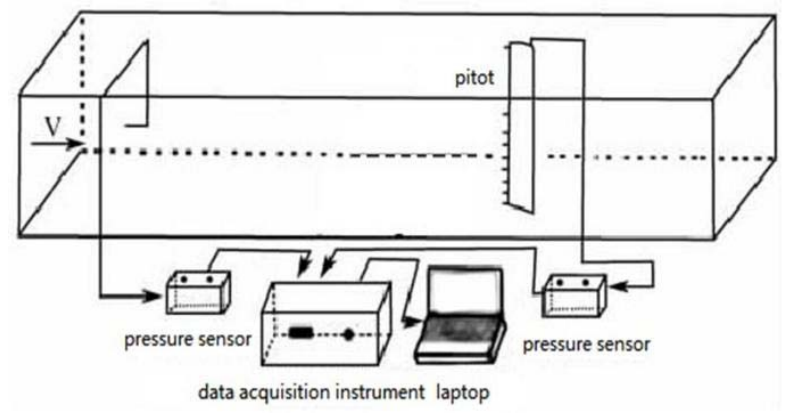

Figure 1. Wind tunnel experiment equipment

Table 1. Information of 8 kinds of different windbreak forest belt structure

\begin{tabular}{|c|c|c|c|c|c|c|c|}
\hline $\begin{array}{l}\text { Forest belt } \\
\text { number }\end{array}$ & Rows & $\begin{array}{c}\text { Tree } \\
\text { number }\end{array}$ & $\begin{array}{l}\text { Proportion of } \\
\text { branches }\end{array}$ & $\begin{array}{l}\text { Plant spacing } \\
{[\mathrm{cm} \times \mathrm{cm}]}\end{array}$ & $\begin{array}{c}\text { Forest } \\
\text { bandwidth }[\mathrm{cm}]\end{array}$ & Density & $\begin{array}{c}\text { Degree of } \\
\text { opacity }\end{array}$ \\
\hline 1 & 2 & 30 & 0.167 & $4 \times 4$ & 8 & 6.250 & 0.3037 \\
\hline 2 & 3 & 45 & 0.113 & $4 \times 4$ & 12 & 6.250 & 0.1764 \\
\hline 3 & 4 & 58 & 0.102 & $4 \times 4$ & 15 & 6.444 & 0.1323 \\
\hline 4 & 5 & 73 & 0.096 & $4 \times 4$ & 20 & 6.083 & 0.1296 \\
\hline 5 & 3 & 32 & 0.148 & $6 \times 6$ & 16 & 3.333 & 0.4458 \\
\hline 6 & 3 & 23 & 0.208 & $8 \times 8$ & 20 & 1.917 & 0.5106 \\
\hline 7 & 3 & 45 & 0.159 & $4 \times 6$ & 16 & 4.688 & 0.3359 \\
\hline 8 & 3 & 29 & 0.192 & $6 \times 8$ & 20 & 2.417 & 0.4315 \\
\hline
\end{tabular}

\section{Wind Speed Measurement}

In wind tunnel experiment, set the free wind speed gradient to 8,11 and $14 \mathrm{~m} \cdot \mathrm{s}^{-1}$. The plants of different types are respectively placed at the wind tunnel. For each case, the wind speed at 17 
heights are measured $(1 \mathrm{~cm}, 2 \mathrm{~cm}, 3 \mathrm{~cm}, 4 \mathrm{~cm}, 5 \mathrm{~cm}, 6 \mathrm{~cm}, 7 \mathrm{~cm}, 8 \mathrm{~cm}, 9 \mathrm{~cm}, 10 \mathrm{~cm}, 11 \mathrm{~cm}, 12 \mathrm{~cm}, 13 \mathrm{~cm}$, $14 \mathrm{~cm}, 16 \mathrm{~cm}, 18 \mathrm{~cm}$ and $20 \mathrm{~cm})$.Meanwhile, we measure the average wind velocities for 17 locations along a center line perpendicular to the shelter belt locations with windward $(0,1 \mathrm{H}, 2 \mathrm{H}, 3 \mathrm{H}, 4 \mathrm{H}$ and $5 \mathrm{H}$ )and leeward $(0,1 \mathrm{H}, 2 \mathrm{H}, 3 \mathrm{H}, 4 \mathrm{H}, 5 \mathrm{H}, 6 \mathrm{H}, 7 \mathrm{H}, 8 \mathrm{H}, 9 \mathrm{H}$ and $10 \mathrm{H})$, where $\mathrm{H}$ is the average tree heights and is equivalent to $10 \mathrm{~m}$ actually (refer with: Fig. 2)

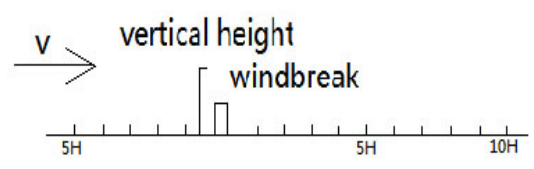

Figure 2. Position of measurement locations for shelter belt in wind tunnel

\section{Model Establishment}

In order to establish a wind speed relationship simulation model between average wind velocities after the forest belt, height and the average speed before the windbreak belt. First, we calculate the average wind speed of different heights before $0-5 \mathrm{H}$ in the shelter belt and after $0-10 \mathrm{H}$ in the forest belt. Second, check the speed data and analyze data correlation. Finally, the speed model is established by least squares linear regression, ridge regression and elastic network algorithm.

\section{Data Outliers Check}

Outliers are defined as individual values in the sample that deviate significantly from the rest of the observation. Box plots display discrete distribute of data and quickly identify outliers ${ }^{[9,10]}$.Five values from a set of data are conventionally used; the upper $\left(\mathrm{Q}_{\mathrm{u}}\right)$ and lower $\left(\mathrm{Q}_{\mathrm{d}}\right)$ extremes, the upper $\left(\mathrm{Q}_{1}\right)$ and lower $\left(\mathrm{Q}_{3}\right)$ quartiles, and the median $\left(\mathrm{Q}_{2}\right)$.(refer with: Eq. 1, Eq. 2,Eq. 3) . A value greater than $\mathrm{Q}_{\mathrm{u}}$ and less than $\mathrm{Q}_{\mathrm{d}}$ is defined as an abnormal value.

$$
\begin{aligned}
& \mathrm{Q}_{\mathrm{u}}=\mathrm{Q}_{1}+1.5 \mathrm{IQR} \\
& \mathrm{Q}_{\mathrm{d}}=\mathrm{Q}_{3}-1.5 \mathrm{IQR} \\
& \mathrm{IQR}=\mathrm{Q}_{1}-\mathrm{Q}_{3}
\end{aligned}
$$

In Eq. 1, Eq. 2, Eq. 3, IQR is the length of the box.

Because the abnormal value will affect the analysis of the data and the establishment of the model, the outliers of the wind speed sample data is judged by the box plot. By analyzing the figure 3(refer with: Fig. 3), there are no outliers in each set of data.

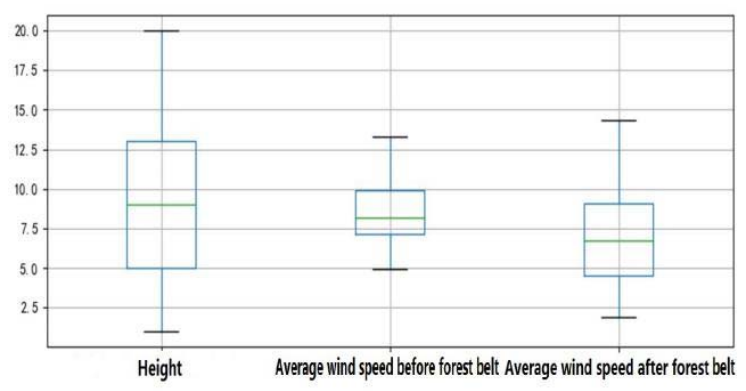

Figure 3. Box plot of data

\section{Wind Speed Model Establishment}

After the outliers are checked, we establish the wind speed model the average wind speed of $0-5 \mathrm{H}$ before windbreak and heights are defined as independent variables and the average wind speed of $0-10 \mathrm{H}$ after the belt is the dependent variable. We divided 272 test data into 218 training samples and 54 test samples. On the training samples, we obtain the correlation coefficient between each 
independent variable and the dependent variable, analyze the necessity of establishing a model between the three variables, and use 3 kinds of multiple regression algorithms to establish the wind speed model.

\section{Correlation Analysis}

According to the correlation analysis between the independent variable and the dependent variable, the correlation coefficient between the height and the average wind speed of $0-10 \mathrm{H}$ after the forest belt is 0.8057 , and the correlation coefficient between the average wind speed of $0-5 \mathrm{H}$ and the dependent variable before the forest belt is 0.8306 . There is a strong correlation between the two influencing factors and the dependent variable, so it makes sense to establish a model between the three(refer with: Fig. 4).

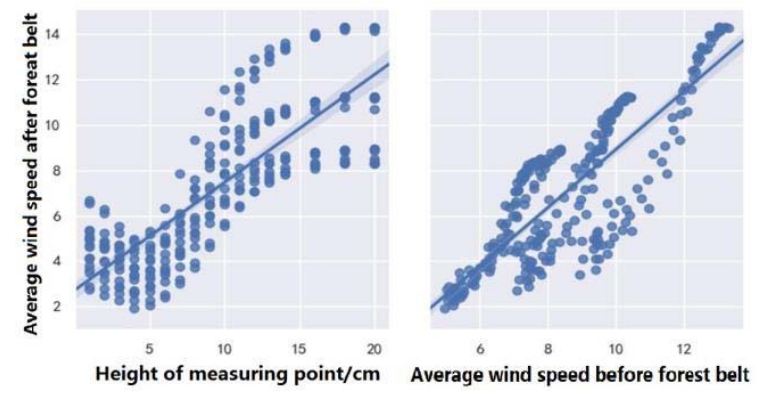

Figure 4. Correlation between two independent variables and dependent variables

\section{Model Establishment}

Simple linear regression is a statistical analysis method that can determine the quantitative relationship between two or more variables. When two or more variables are included in the regression analysis, the fitting relationship is no longer a "straight line" but a "face" or "hyper plane", so it is called multiple linear regression. Wind speed model was established for 218 training samples by three regression methods.

We set the average wind speed of $0-5 \mathrm{H}$ before the windbreak forest belt as the influence factor $\mathrm{x}_{1}$, and the height is the influence factor $\mathrm{x}_{2}$, then the average wind speed of $0-10 \mathrm{H}$ after the forest belt is the dependent variable $\mathrm{h}_{\theta}\left(\mathrm{x}^{(\mathrm{i})}\right)$. The wind speed model format is Eq. 4.

$$
\mathrm{h}_{\theta}\left(\mathrm{x}^{(\mathrm{i})}\right)=\theta_{0}+\theta_{1} \mathrm{X}^{(\mathrm{i})}+\theta_{2} \mathrm{x}^{(\mathrm{i})}
$$

In Eq. $4, \mathrm{i}=1,2, \ldots, \mathrm{m}$ represents number of samples, $\theta_{0}$ is the equation intercept, and $\theta_{1}, \theta_{2}$ are the coefficients of the influence factors $\mathrm{X} 1, \mathrm{X} 2$, respectively.

\section{Establishing a Wind Speed Model Based on Least Squares Linear Regression}

The least squares method ${ }^{[11,12]}$ constructs a loss function $(\mathrm{J}(\theta))$ used as the constraint condition to mesure the error between the predicted value and the true value, and the loss function $J(\theta)$ is adjusted to minimize it so that we can obtain the optimal coefficient of the influence factor (refer with: Eq. 5).

$$
J(\theta)=\frac{1}{2 m} \sum_{i=1}^{m}\left(h_{\theta}\left(x^{(i)}\right)-(y)^{(i)}\right)^{2}
$$

In Eq. 5, $\mathrm{m}$ is number of samples, $\mathrm{h}_{\theta}\left(\mathrm{x}^{(\mathrm{i})}\right)$ is the predicted value of the its sample, and $\mathrm{y}^{(\mathrm{i})}$ is the true value of the its sample. The wind speed model is Eq. 6:

$$
y=-3.51667+0.90426 x_{1}+0.30931 x_{2} \quad\left(R^{2}=0.90676\right)
$$

\section{Establishing a Wind Speed Model Based on Ridge Regression}

Ridge regression ${ }^{[13,14]}$ can solve the multicollinearity problem between independent variables. The least squares method is very sensitive to the noise in the input variable. The slight change of the 
independent variable will cause a large change in the output result. The ridge regression can add the L2 paradigm to the loss function. To solve this problem, the loss function is as in Eq. 7.

$$
J(\theta)=\frac{1}{2 m} \sum_{i=1}^{m}\left(h_{\theta}\left(x^{(i)}\right)-y^{(i)}\right)^{2}+\lambda \sum_{j=1}^{n} \theta_{j}^{2}
$$

In Eq. $7, \lambda$ is a regularization parameter, $\mathrm{j}=1,2$ is the number of impact factor $\left(\mathrm{x}_{1}, \mathrm{x}_{2}\right), \theta_{\mathrm{j}}$ is the coefficient factor $\left(\theta_{1}, \theta_{2}\right)$.

When $\lambda=0.1$, the loss function value is the smallest, and the wind speed model(refer with: Eq. 8) established by the ridge regression algorithm:

$$
\mathrm{y}=-3.51582+0.90414 \mathrm{x}_{1}+0.30932 \mathrm{x}_{2} \quad\left(\mathrm{R}^{2}=0.90676\right)
$$

\section{Establishing a Wind Speed Model Based on Elastic Networks}

Elastic Net ${ }^{[15,16]}$ is a continuous iterative linear regression method using the L1 paradigm and the L2 paradigm as a priori regular terms. The 11_ratio parameter can be used to control the convex combination of L1 and L2, and 11_ratio is the elastic mesh mixing parameter. The loss function is of Eq. 9.

$$
J(\theta)=\frac{1}{2 m} \sum_{i=1}^{m}\left(h_{\theta}\left(x^{(i)}\right)-y^{(i)}\right)^{2}+\lambda_{1} \sum_{j=1}^{n} \theta_{j}^{2}+\lambda_{2} \sum_{j=1}^{n}\left\|\theta_{j}\right\|
$$

In Eq. $9, \lambda_{1}$ and $\lambda_{2}$ are regularization parameters.

When 11 ratio $=0.7, \lambda_{1}=0.02801$ and $\lambda_{2}=0.13070$, the loss function value is the smallest, and the wind speed model(refer with: Eq. 10) established by the elastic network:

$$
y=-3.15764+0.85962 x_{1}+0.31212 x_{2} \quad\left(R^{2}=0.90602\right)
$$

\section{Wind Speed Model Test and Selection}

In order to test the wind speed simulation model, this study used independent test samples to assess the model estimation ability. We use the training set, test set determination coefficient $\left(\mathrm{R}^{2}\right)$ and root mean square error (RMSE) as the evaluation indicators, and select the optimal wind speed model by comparing the evaluation indicators. We use 54 data to complete the test of the model.

Table 2. Comparison table of three kinds of multiple linear regression method

\begin{tabular}{cccc}
\hline Method & Training set $\left(\mathrm{R}^{2}\right)$ & Test set $\left(\mathrm{R}^{2}\right)$ & RMSE \\
\hline Least squares & 0.90676 & 0.90059 & 1.05492 \\
Ridge regression & 0.90676 & 0.90060 & 1.05490 \\
Elastic Net & 0.90602 & 0.90135 & 1.05092 \\
\hline
\end{tabular}

According to table 2(refer with: Table 2), it can be seen that the $\mathrm{R}^{2}$ and RMSE of the three models are not significantly different, and the coefficient of determination is above $90 \%$. The $\mathrm{R}^{2}$ of the model established by using the elastic network is closer to the training set and the test set, and the RMSE is 1.05092. Therefore, the elastic network is used to construct the wind speed model(refer with: Fig. 5). 


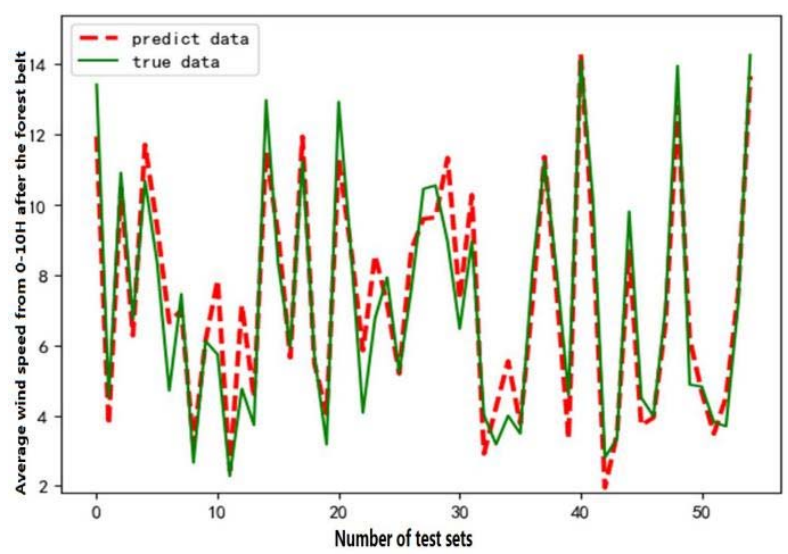

Figure 5. ElasticNet true and predicted values of test set samples

\section{Conclusions}

(1)The wind speed model can be established by least squares method, ridge regression and elastic network algorithm. At free wind speeds of 8,11 and $14 \mathrm{~m} \cdot \mathrm{s}^{-1}$, the average wind speed after $0-10 \mathrm{H}$ the forest belt can be estimated by the average wind speed of $0-5 \mathrm{H}$ before the forest belt and height.

(2)The wind speed model established by the elastic network is better and the generalization ability is better.

\section{Acknowledgement}

This work is supported by Key Technologies and Demonstration of Desertification Land Management in the Wind and Sand Source Area of Beijing-Tianjin-Hebei(no.2016YFC0500802-06), Hebei Province Higher Education Science and Technology Research Project(no.ZD2016158), Introducing Talent Research Project of Agricultural University of Hebei(no. YJ201829) and Hebei Youth Talents Project(no. BJ2019008).

\section{References}

[1] Z. Zuo, Z.B. Pan, A.D. Zhang, D. Yu and J.Y. Zhou, Spatial wind speed and surface wind erosion characteristics of farm-shelter forest network in arid sandy area, J.EI. Transactions of the Chinese Society of Agricultural Engineering. 34 (2018) 135-141.(in Chinese)

[2] J.P. Bitog, I.B. Lee, H.S. Hwang, M.H. Shin, S.W. Hong, I.H. Seo, K.S. Keon, E. Mostafa and Z.Z. Pang. Numerical simulation study of a tree windbreak, J.SCI. Biosystems engineering. $111(2012): 40-48$.

[3] S. Zhang, G.D. Ding, G.L. Gao, Y.Y. Zhao, Y.F. Bao and M.H. Yu, Influence of Wind Direction and Speed on the Windbreak Efficiency of Farmland Shelterbelt Networks Based on Mathematical Expectation, J. Journal of Xiamen University(Natural Science). 57 (2018) 510-516.(in Chinese)

[4] Q.H. Niu, B. Peng, G.Q. Lu and J.C. Gu, Windbreak Efficiency of Pasture Shelterbelt in Bashang Area of Hebei Province, J.Bulletin of Soil and Water Conservation. 38 (2018) 114-117.(in Chinese)

[5] M. Rosenfeld, G. Marom and A. Bitan, Numerical simulation of the airflow across trees in a windbreak, J.SCI. Boundary-layer meteorology. 135 (2010) 89-107.

[6] H. Takahashi, Wind tunnel test on the effect of width of windbreaks on the wind speed distribution in leeward, J.SCI. Journal of Agricultural Meteorology. 33 (1978) 183-187. 
[7] H. Cheng, K.D. Zhang, C.C. Liu, X.Y. Zou, L.Q. Kang, T.L. Chen, W.W. Huang and Y. Fang, Wind tunnel study of airflow recovery on the lee side of single plants, J.SCI. Agricultural and forest meteorology. 263 (2018) 362-372.

[8] J.P. Lee, E.J. Lee, S.J, Shelter effect of a fir tree with different porosities, J.SCI. Journal of Mechanical Science and Technology. 28 (2014) 565-572.

[9] R. Mcgill, J.W. Tukey and W.A. Larsen, Variations of box plots, J.SCI. The American Statistician. 32 (1978) 12-16.

[10] H. Zhou, B. Lin, J.Q. Qi, L.H. Zheng and Z.C. Zhang. Analysis of correlation between actual heating energy consumption and building physics, heating system, and room position using data mining approach, J.SCI. Energy and Buildings. 166 (2018) 73-82.

[11] L.Y. Zhou, Y.C. Yuan, Y.F. Song and B. Wang, Research on estimation of wheat chlorophyll using image processing technology, J. Journal of Hebei Agricultural University. 41 (2018) 105-109.(in Chinese)

[12] X.X Guo, G.H. Zhou and H. Cheng. Research on weight forecast of cauliflower based on linear regression model, J. Journal of Hebei Agricultural University. 42 (2019) 126-130.(in Chinese)

[13] Q. Wang, L.F. Leng and Y.L. Chang, Improvement of Ridge Regression and Principal Component Regression in Stock Index Tracking, J. Journal of Chongqing University of Technology(Natural Science), 32 (2018) 212-221.(in Chinese)

[14] E. Vigneau, M. F. Devaux, E. M. Qannari and P. Robert, Principal component regression, ridge regression and ridge principal component regression in spectroscopy calibration, J.SCI. Journal of Chemometrics: A Journal of the Chemometrics Society. 11 (1997) 239-249.

[15] J.O. Ogutu, T. Schulz-Streeck and H.P. Piepho, Genomic selection using regularized linear regression models: ridge regression, lasso, elastic net and their extensions, C.BMC proceedings. 6(2012): S10.

[16] K. Sjöstrand, Matlab implementation of LASSO, LARS, the elastic net and SPCA, J.SCI Software. 6(2005). 